\title{
The Structures of Precipitates in an Mg-0.5 at\% Nd Age-Hardened Alloy Studied by HAADF-STEM Technique
}

\author{
Kaichi Saito ${ }^{1, *}$ and Kenji Hiraga ${ }^{2}$ \\ ${ }^{1}$ Department of Materials Science and Engineering, Akita University, Akita 010-8502, Japan \\ ${ }^{2}$ Institute for Materials Research, Tohoku University, Sendai 980-8577, Japan
}

The crystal structures and microstructures of precipitates formed in an $\mathrm{Mg}-0.5$ at $\% \mathrm{Nd}$ alloy aged at certain temperatures ranging between $170^{\circ} \mathrm{C}$ and $250^{\circ} \mathrm{C}$ are studied in detail by high-angle annular detector dark-field scanning transmission electron microscopy. The precipitation sequence can be presented as $\mathrm{Mg}$-solution $\rightarrow$ GP-zone $\rightarrow \beta^{\prime}$ (orthorhombic) $\rightarrow \beta_{1}$ (fcc). At the early stage of aging (170 ${ }^{\circ} \mathrm{C}$ for $2 \mathrm{~h}$ ), fine precipitates of planar GP-zones appear in parallel to $(100)_{\mathrm{m}}$ planes, with a thickness of sub-nm and a length of 5-15 nm (the subscript letter of $\mathrm{m}$ denotes matrix). With an advance of aging, the GP-zones increasingly grow larger and combine with the neighbours, thus making themselves further prolonged along the directions addressed above. When reaching at the top-stage of aging $\left(170^{\circ} \mathrm{C} \mathrm{for} 100 \mathrm{~h}\right)$, the alloy additionally allows the $\beta^{\prime}$-phase to coexist, taking the form of lens-shape with a thickness of $2-5 \mathrm{~nm}$ and a diameter of $5-15 \mathrm{~nm}$. The $\beta^{\prime}$-phase has an orthorhombic structure $\left(\mathrm{Mg}_{7} \mathrm{Nd}\right)$ with $a=0.64 \mathrm{~nm}, b=1.1 \mathrm{~nm}$, and $c=0.52 \mathrm{~nm}$, which is coherently connected to the matrix. At the stage of over-aging, both the GP-zones and the $\beta^{\prime}$-phase disappear and instead coarse precipitates of the stable $\beta_{1}$-phase $\left(\mathrm{Mg}_{3} \mathrm{Nd}\right.$; fcc) are formed with particular crystallographic relations of $[001]_{\mathrm{m}} / /[110]_{\mathrm{p}}$ and $[110]_{\mathrm{m}} / /[112]_{\mathrm{p}}$ (the subscript letter of $\mathrm{p}$ denotes precipitate).

[doi:10.2320/matertrans.M2011163]

(Received May 31, 2011; Accepted July 15, 2011; Published September 7, 2011)

Keywords: magnesium alloys, precipitation, crystal structure, microstructure, high-angle annular detector dark-field scanning transmission electron microscopy (HAADF-STEM)

\section{Introduction}

The demand for magnesium (Mg)-based alloys is yearly increasing in modern industry. In particular, those containing rare earth (RE) metals have long been in the spotlight of research and development, since they can combine quite low density and remarkably high strength properties. ${ }^{1)}$ Historically, the first step in production and application of Mg-RE alloys began after works of T. E. Leontis ${ }^{2,3)}$ around 1950, dealing with Mg-'misch metal' alloys, where mixing solutes of cerium $(\mathrm{Ce})$, lanthanum $(\mathrm{La})$, and neodymium $(\mathrm{Nd})$ are main constituents. Above all, the solute element of $\mathrm{Nd}$ was found to have a primary effect on their age-hardening. In the late $60 \mathrm{~s}, \mathrm{Mg}$ alloys with Y turned out to show even higher strength properties than $\mathrm{Mg}-\mathrm{Nd}$ system. ${ }^{4,5)}$ A series of these discoveries stimulated continuation of the investigations on Mg-RE alloys, especially those with combined additions of $\mathrm{Nd}, \mathrm{Y}$ and some other metals. In fact, age-hardened alloys based on $\mathrm{Mg}-\mathrm{Y}-\mathrm{Nd}$ system are in current commercial use and, for examples, those designated as WE43 and WE54 are two of the most successful products, although their precipitation behaviour is still a controversial issue. ${ }^{6-8)}$

It is undoubted that conventional transmission electron microscopy (TEM) including high resolution microscopy (HRTEM) have, thus far, made a great contribution to reveal local structural and microstructural features of precipitates in various age-hardened alloys. However, these ordinary TEM techniques alone are not powerful enough for direct determination of crystal structures as well as microstructures of such extremely small substances involving coherent structural relationship to the matrix. In recent years, an alternative technique capable of imaging individual heavier elements in

*Corresponding author, E-mail: ksaito@ipc.akita-u.ac.jp alloys, which is referred to as high-angle annular detector dark-field scanning transmission electron microscopy (HAADF-STEM), has demonstrated its ability to illuminate real crystal structures of various alloys. Combined technique of TEM, HRTEM and HAADF-STEM, indeed, have successfully become utilized to elucidate the precipitation behaviour of various $\mathrm{Mg}-\mathrm{RE}$ alloys, e.g. $\mathrm{Mg}-\mathrm{Y},{ }^{9)} \mathrm{Mg}-$ $\mathrm{Gd},{ }^{10,11)} \mathrm{Mg}-\mathrm{Gd}-\mathrm{Zn},{ }^{12-14)} \mathrm{Mg}-\mathrm{Sm}^{15)}$ and $\mathrm{Mg}$-Dy ${ }^{16)}$ systems. The present microscopic study focuses on the precipitation arising from an $\mathrm{Mg}-\mathrm{Nd}$ binary alloy. There are some literature dealing with this subject, but it seems that the characterization of its real precipitation behaviour has been far from completed. ${ }^{17-19)}$ The HAADF-STEM technique is, thus, expected to become efficiently utilized to solve the issue.

\section{Experimental Procedures}

An alloy with a nominal composition of 99.5 at $\% \mathrm{Mg}$ 0.5 at\% Nd was prepared by melting $\mathrm{Mg}(99.9 \%), \mathrm{Nd}(99.9 \%)$ metals by induction heating under an $\mathrm{Ar}$ gas in a carbon crucible. The alloy was homogenized at $520^{\circ} \mathrm{C}$ for $2 \mathrm{~h}$ and then quenched immediately in water. Subsequently, the quenched alloy was divided into several parts, and the parts were subjected to aging treatments at certain temperatures ranging between $170^{\circ} \mathrm{C}$ and $250^{\circ} \mathrm{C}$ for various lengths of time. The hardening responses of these alloys upon aging at a temperature of $170^{\circ} \mathrm{C}$ were determined by measuring Micro-Vickers hardness number at a load of $0.1 \mathrm{kgf}$ (MATSUZAWA MMT-X3). The hardness number was taken as the average of ten fairly equal values. Based on the series of data, a plot of Vickers hardness number versus aging time of logarithmic scale was made and, in addition, a standard deviation for each series of data was calculated and 
presented as an error bar in the plot. Specimens for TEM were cut from the as-aged alloys and thinned by mechanical polishing, and finally completed by ion-milling. HAADFSTEM as well as HRTEM images were taken by a $200 \mathrm{kV}$ electron microscope (JEM-2010F), which is equipped with a field emission gun in the scanning transmission electron microscope mode, and a $400 \mathrm{kV}$ electron microscope (JEM4000EX). In HAADF-STEM observations, a beam probe with a half width of about $0.2 \mathrm{~nm}$ was scanned on thin specimens.

\section{Results and Discussion}

\subsection{Morphological features of precipitates resulting at different aging stages}

Figure 1 shows an age-hardening response of the $\mathrm{Mg}$ 0.5 at $\% \mathrm{Nd}$ alloy which was solution-treated at $520^{\circ} \mathrm{C}$ and subsequently aged at $170^{\circ} \mathrm{C}$. In this result, the alloy sample is found to have the hardness maximum recorded around $100 \mathrm{~h}$ and subsequently decreased with prolonged aging. On the basis of this result, in addition to three different under-aged alloys at $170^{\circ} \mathrm{C}$ for $30 \mathrm{~min}, 2 \mathrm{~h}$ and $100 \mathrm{~h}$, three different over-aged alloys at $200^{\circ} \mathrm{C}$ for $10 \mathrm{~h}, 250^{\circ} \mathrm{C}$ for $2 \mathrm{~h}$ and $9 \mathrm{~h}$, were prepared for the following microscopic investigations.

Figure 2 shows a set of HAADF-STEM images obtained

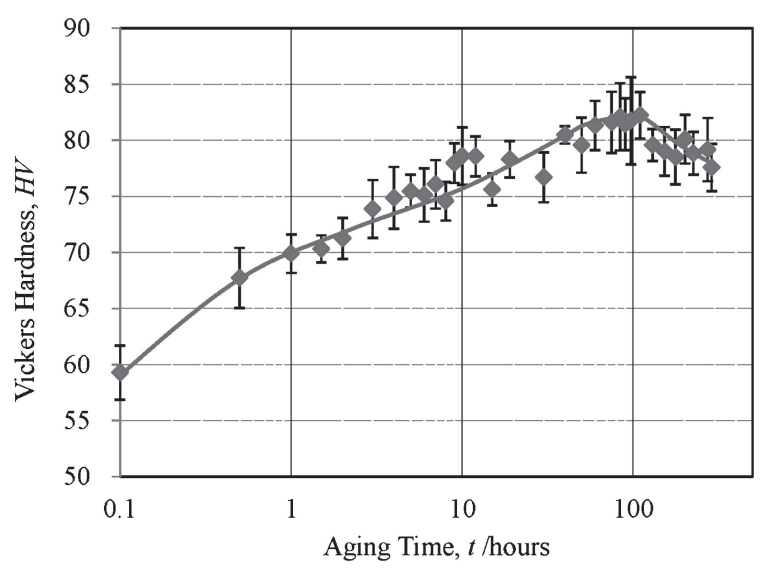

Fig. 1 Age-hardening response of $\mathrm{Mg}-0.5$ at $\% \mathrm{Nd}$ alloy obtained at $170^{\circ} \mathrm{C}$ with aging time. from the three as-aged alloys at $170^{\circ} \mathrm{C}$, taken with the incident beam parallel to the $[001]_{\mathrm{m}}$ direction of the $\mathrm{Mg}$ matrix: the as-aged alloys at $170^{\circ} \mathrm{C}$ for $30 \mathrm{~min}(\mathrm{a}), 2 \mathrm{~h}(\mathrm{~b})$ and $100 \mathrm{~h}(\mathrm{c})$. The index of this viewing direction as well as all the others will, hereafter, be designated as $[001]_{\mathrm{m}}$ and so on, where the subscript letter ' $\mathrm{m}$ ' denotes the Mg-matrix. The HAADF-STEM imaging technique allows us to recognize positions of heavy atoms as well as their enriched regions as bright contrast, thus providing microstructural information related to $\mathrm{Nd}$-segregation in the Mg-matrix. Figure 2(a) shows an initial sign of Nd-segregation in the matrix: the presence of many bright and roundish contrasts with an average extension of several $\mathrm{nm}$ can be weakly recognized all over the matrix. By contrast, the other alloys with longer aging treatments are found to have more sharply-recognized contrasts associated with the Nd-segregation. The as-aged alloy for $2 \mathrm{~h}$ has many fine precipitates taking the form of liner and/or curved segments with a thickness of sub-nm and a length ranging between 5 and $15 \mathrm{~nm}$. As will be detailed later, it was demonstrated by separate observations that these precipitates have a certain ordered structure of $\mathrm{Nd}$ atoms in the Mg-matrix, but lacking in widely-extended periodic order. They can, therefore, be regarded as a kind of GP-zones involving the atomic ordering. The precipitates of the GPzone, which appear to take the form of thin-plates, are approximately extended along the three $[100]_{\mathrm{m}}$-type directions in the Mg-lattice. Note that a triad set of arrows in Fig. 2(b) (and in all the other figures as well) indicates the $[100]_{\mathrm{m}}$-type directions. When reaching at the stage of topaging, the alloy has many of the GP-zones grown larger and combined with the neighbours, thus making themselves further continued as long as $20-50 \mathrm{~nm}$ along the three $[100]_{\mathrm{m}}$ directions (see Fig. 2(c)). Besides, another type of precipitates (designated as $\beta^{\prime}$ ) with appreciable thicknesses become revealed with their extensions prolonged along three equivalent directions of the Mg-matrix, not in parallel to the $[100]_{\mathrm{m}}$-type but rather to the $[210]_{\mathrm{m}}$-type directions. They exhibit oval shapes in this viewing direction with a width of $2-5 \mathrm{~nm}$ and a length of $5-15 \mathrm{~nm}$, several of which are indicated by arrowheads in Fig. 2(c). With an advance of under-aging, the $\beta^{\prime}$-phase was found to become increasingly larger in size and number. These results provide the evidence that the age-hardening effect in the $\mathrm{Mg}-\mathrm{Nd}$ alloy is
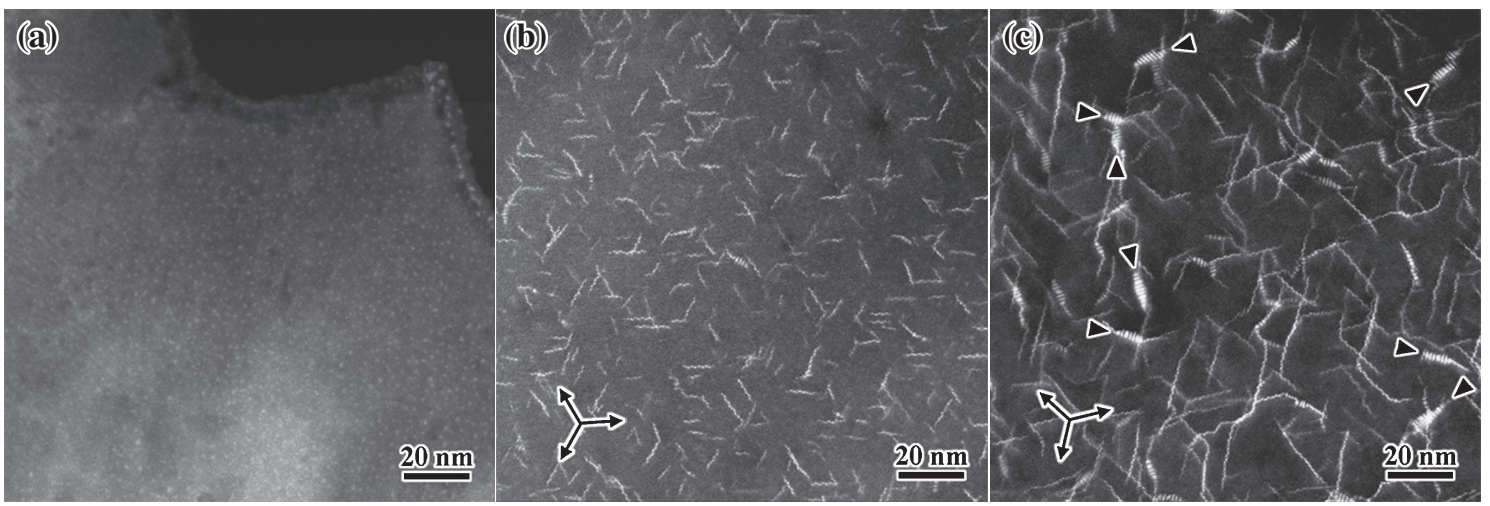

Fig. 2 HAADF-STEM images showing microstructures of three different under-aged alloys, taken with the $[001]_{\mathrm{m}}$ incidence: (a) $170^{\circ} \mathrm{C}$ for $30 \mathrm{~min}$, (b) $170^{\circ} \mathrm{C}$ for $2 \mathrm{~h}$, (c) $170^{\circ} \mathrm{C}$ for $100 \mathrm{~h}$ (top-aging). Triad sets of arrows in (b), (c) indicate the three [100 $]_{\mathrm{m}}$-type directions of the Mg-matrix. 


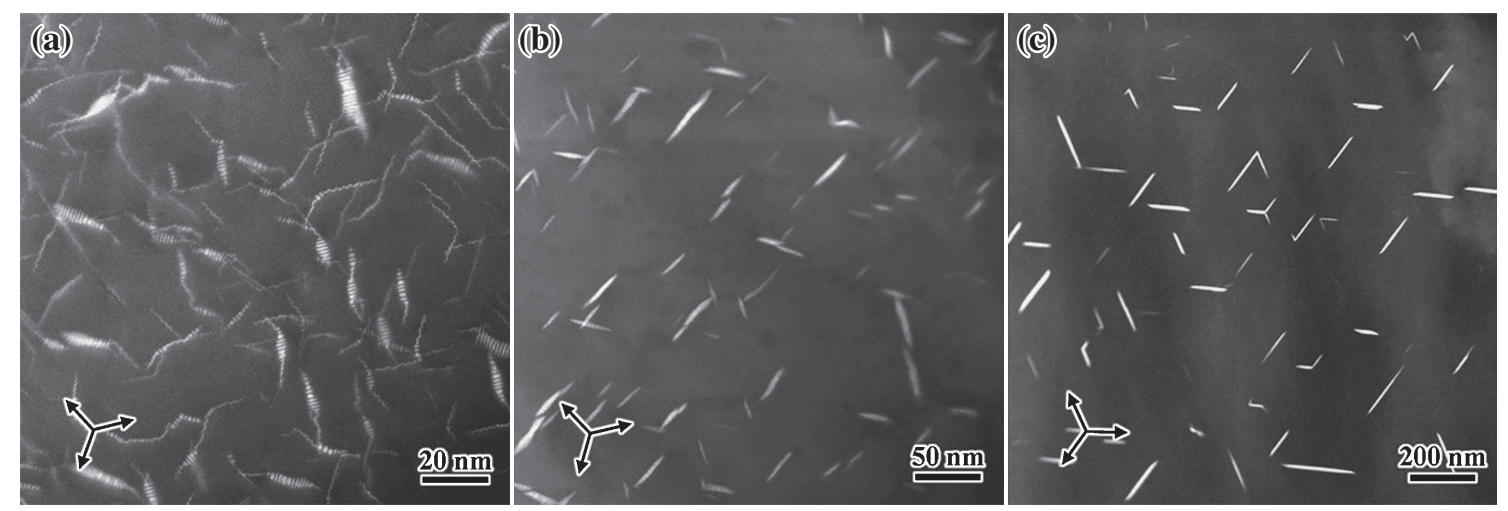

Fig. 3 HAADF-STEM images showing microstructures of three different over-aged alloys, taken with the [001 $]_{\mathrm{m}}$ incidence: (a) $200^{\circ} \mathrm{C}$ for $10 \mathrm{~h}$, (b) $250^{\circ} \mathrm{C}$ for $2 \mathrm{~h}$, (c) $250^{\circ} \mathrm{C}$ for $9 \mathrm{~h}$. Note that three of the $[100]_{\mathrm{m}}$-type directions are indicated by a triad set of arrows in each image.

maximized, when such a unique microstructural feature, which is characterized by a network of the long-lasting GPzones decorated by the $\beta^{\prime}$-precipitates, is prominent.

Figure 3 shows a set of HAADF-STEM images obtained from the three over-aged alloys with the $[001]_{\mathrm{m}}$ incidence, which were recorded with different magnifications: the asaged alloys at $200^{\circ} \mathrm{C}$ for $10 \mathrm{~h}(\mathrm{a}), 250^{\circ} \mathrm{C}$ for $2 \mathrm{~h}(\mathrm{~b})$ and $250^{\circ} \mathrm{C}$ for $9 \mathrm{~h}$ (c). Triad set of arrows in the figures, likewise, indicate the three equivalent $[100]_{\mathrm{m}}$-type directions of the $\mathrm{Mg}$-matrix. In each image, there are a number of as-grown precipitates enriched by $\mathrm{Nd}$ atoms distributed in the matrix, having a similar morphological feature prolonged along three equivalent directions of the Mg-matrix, although they progressively grow larger by stages. It was, however, found that the precipitates resulting at the respective stages are essentially different in phase. The over-aged alloy presented by Fig. 3(a) essentially has the same constituent phases to those observed in Fig. 2(c): the alloy still has both the GPzones and the $\beta^{\prime}$-phase coexisting in the matrix, although the latter is predominant over the former. When aged at $250^{\circ} \mathrm{C}$ for $2 \mathrm{~h}$, the GP-zones completely disappear and instead the $\beta^{\prime}$-phase become dominant over the matrix (Fig. 3(b)). At the final stage (Fig. 3(c)), the third type of precipitates, which is designated as $\beta_{1},{ }^{7)}$ replace the $\beta^{\prime}$ precipitates, having plate-shapes extended along the $[100]_{\mathrm{m}}$ directions. This will be detailed later again with Figs. 9-11.

\subsection{Structural features of precipitates resulting at different aging stages}

Local structures of such fine precipitates as mentioned above were thoroughly examined by atomic-scale HAADFSTEM imaging technique. Figure 4 are a set of atomic-scale HAADF-STEM images targeting a local area containing planar precipitates which we previously referred to as GPzones. The imaging was made for the as-aged alloy at $170^{\circ} \mathrm{C}$ for $2 \mathrm{~h}$ with the $[001]_{\mathrm{m}}$ incidence. Figures $4(\mathrm{~b})-4(\mathrm{~d})$ are enlarged images from local areas indicated by arrowheads attached with letters of B, C and D in Fig. 4(a), respectively. In Fig. 4(a), there exist many series of bright dots, each of which corresponds to an individual atom column of $\mathrm{Nd}$ atoms, making the continuation of straight and/or curved lines. More specifically, these bright dots are also seen to take the form of zigzag-chains, most of which are aligned approximately along the three $[100]_{\mathrm{m}}$-type directions indi- cated by a triad of arrows in Fig. 4(a). Occasionally, a hexagonal array of bright dots with its side length of $0.37 \mathrm{~nm}$ is also found in a few places (Fig. 4(b)). These precipitates apparently have a certain structural order, but lacking in periodic arrangements in wide regions. Close examinations of these images make us realize that the zigzag-chains are constructed of a series of connected 'zigzag-components' of bright dots, each of which is based on a group of either 3 or 4 individual dots separated at regular intervals of $0.37 \mathrm{~nm}$. According to this interpretation, the zigzag-chains spotlighted in Figs. 4(c) and 4(d), for examples, can be described as the series of zigzag-components with 3-3-3-4 and 4-4-4 sequences in the order from top to bottom, respectively. These observations have arrowed us to directly derive the structure models of the precipitates.

Figure 5 illustrates three structure models relevant to the precipitates appearing in Fig. 4, which are presented in the $[001]_{\mathrm{m}}$ projection and with the $[100]_{\mathrm{m}}$ direction parallel to the horizontal. Each model is based on the ordering of $\mathrm{Nd}$ atoms, which is activated in second nearest neighbour positions defined in the hcp Mg-lattice. This ordering effect is responsible for the formation of characteristic arrays of RE atom columns at regular intervals of $0.37 \mathrm{~nm}$, such as the zigzag array and the hexagonal array observed in Fig. 4. The ordered structures indicated by dotted lines in Figs. 5(a), 5(b) and 5(c) have good correspondences to the contrast features appearing in Figs. 4(c), 4(d) and 4(b), respectively. It should be noted here that assuming that one of the atomic positions present in the lattice is the origin in the figure, there are basically two different types of second nearest neighbour positions defined around the origin: one type is of a particular set of 3 positions existing on the same close-packed plane, one of which is represented by an arrow \#1, and the other type is of those on the different close-packed plane represented by an arrow \#2. It follows then that adjacent $\mathrm{Nd}$ atoms lying within every zigzag-component indicated by dotted lines are located in the second nearest neighbour positions specified by the arrow \#2, while adjacent $\mathrm{Nd}$ atoms belonging respectively to separate zigzag-components are located in those specified by the arrow \#1. As was addressed earlier, this ordering effect was only found in a short range and not activated in wide regions. It is, therefore, reasonable to claim that the precipitates, especially of the type of zigzag-chains, are regarded as the GP-zones but not any crystalline phases. 

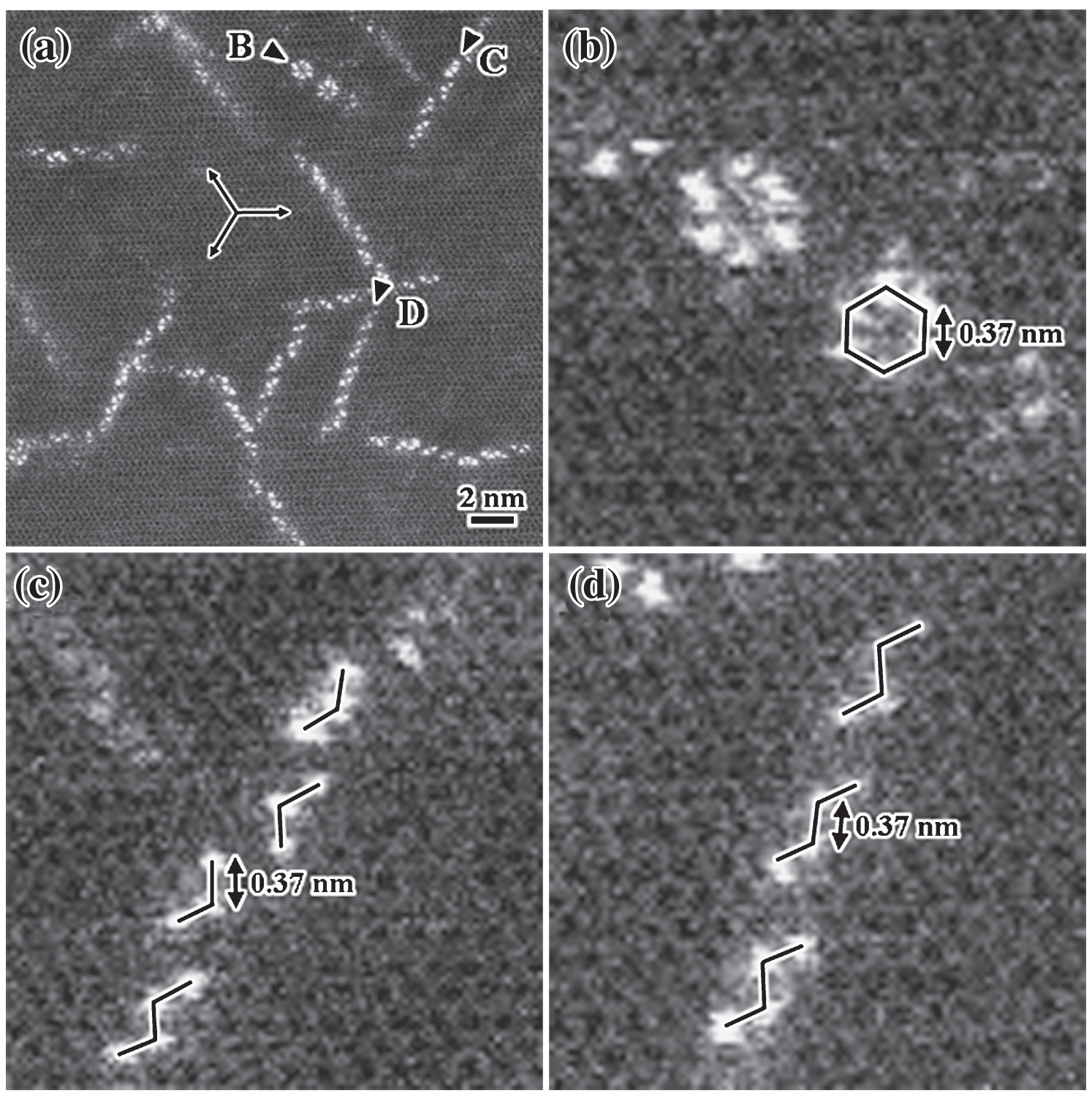

Fig. 4 Atomic-scale HAADF-STEM images obtained from the as-aged alloy at $170^{\circ} \mathrm{C}$ for $2 \mathrm{~h}$, taken with the incident beam parallel to the $[001]_{\mathrm{m}}$ direction: the image in an intermediate magnification (a) and the enlarged images from local regions indicated by arrowheads with letters of B (b), C (c) and D (d). Note that three of the $[100]_{\mathrm{m}}$-type directions are indicated by a triad set of arrows in (a).

Typical microstructures and local structures of precipitates observable at the stage of top-aging are presented in Fig. 6. Figures 6(a) and 6(b) are HAADF-STEM [001 $]_{\mathrm{m}}$-images recorded at different magnifications and, in particular, the latter reveals a contrast feature arising from the $\beta^{\prime}$ precipitate, which is enlarged from a region marked by a square in Fig. 6(a). At this aging stage, the $\beta^{\prime}$-precipitates are found to have oval shapes with a length of $5-15 \mathrm{~nm}$ and a width of $2-5 \mathrm{~nm}$, extending along the $[210]_{\mathrm{m}}$-type directions. In Fig. 6(b), one can see characteristic contrast showing a parallel set of zigzag array of bright dots, which are equally distanced apart by $1.1 \mathrm{~nm}$. A similar contrast feature could result from those of the other Mg-RE alloys such as Mg-Y, $\mathrm{Mg}-\mathrm{Gd}$ and Mg-Dy ${ }^{9-11,16)}$ It has, however, proved that an essential difference exists in the structures between the Mg$\mathrm{Nd}$ and the other systems, as will be detailed below. A rectangle line indicated with letters of $a$ and $b$ in Fig. 6(b) corresponds to a structure unit of the $\beta^{\prime}$-phase of the $\mathrm{Mg}-\mathrm{Nd}$ system. Note that the $\beta^{\prime}$-grain presented in Fig. 6(b) has a defect region where some groups of the hexagonal arrays coexist (see the contrast feature indicated by a hexagonal line in the figure). Figure 7 is a schematic figure showing three different types of structure models of the precipitates resulting at the stage of top-aging in various Mg-RE alloys and, especially, Fig. 7(b) is the one proposed for the Mg-Nd system. They are all illustrated in the $[001]_{\mathrm{m}}$ projection and with the $[210]_{\mathrm{m}}$ direction parallel to the horizontal. The structures of the precipitates in many Mg-RE systems, in common, are based on definite long range ordering of RE atoms: the RE atoms occupy 'particular sets' of second nearest neighbour positions in the $\mathrm{Mg}$ lattice, so that a parallel set of zigzag arrays of $\mathrm{RE}$ atom columns is observable at regular intervals of $1.1 \mathrm{~nm}$, when viewed in the $[001]_{\mathrm{m}}$ projection. Additionally, the hexagonal array of bright dots is one of the common objects as well. The resultant as-grown structures, however, are rather variable depending on the solute elements. In such alloys as Mg-Y, $\mathrm{Mg}-\mathrm{Gd}$ and $\mathrm{Mg}-\mathrm{Dy}$, adjoining zigzag arrays are alternatingly 
inverted one after another (note that black and white arrows in Fig. 7(a) indicate one zigzag array and its inversion, respectively), and the resulting structure, hereby, has an orthorhombic unit with lattice constants of $a=a_{0}=$ $0.64 \mathrm{~nm}, b=4 \sqrt{3} a_{0}=2.28 \mathrm{~nm}$ and $c=c_{0}=0.52 \mathrm{~nm}$ and its atomic ratio of $\mathrm{Mg}_{7} \mathrm{RE}^{9-11,16)}$ By contrast, the precipitate structure resulting from the $\mathrm{Mg}-\mathrm{Nd}$ system (Fig. 7(b)) is constructed of the zigzag arrays at the same intervals but

(a)

$0^{0} 0^{\circ} 0^{\circ} 0^{\circ} 0^{\circ} 0^{\circ} 0^{\circ} 0^{\circ} 0^{\circ} 0^{\circ} 0^{\circ}$

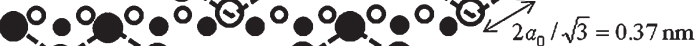

$0^{\circ} \theta^{\circ} 0^{\circ} 0^{\circ} 0^{\circ} 0^{\circ} 0^{\circ} 0^{\circ} 0^{\circ}$

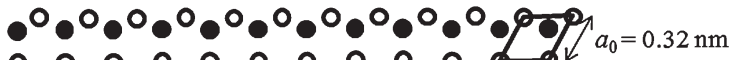

$0^{\circ} 0^{\circ} 0^{\circ} 0^{\circ} 0^{\circ} 0^{\circ} 0^{\circ} 0^{\circ} e^{\circ}$

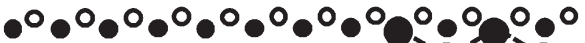

(b)

$0^{\circ} 0^{\circ} 0^{\circ} 0^{\circ} 0^{\circ} 0^{\circ}$

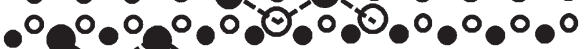

$0^{\circ} 0^{\circ} \mathrm{O}^{\circ} \mathrm{O}^{\circ} 0^{\circ} 0^{\circ} 0^{\circ} 0^{\circ} 0^{\circ} 0^{\circ}$

$\mathrm{O}^{\circ} \mathrm{O}^{\circ} \mathrm{O}^{\circ} \mathrm{O}^{\circ} \mathrm{O}^{\circ} \mathrm{O}^{\circ} \mathrm{O}^{\circ} \mathrm{O}^{\circ} \mathrm{O}^{\circ} \mathrm{O}^{\circ} \mathrm{O}$

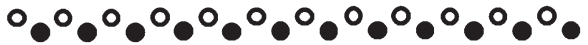

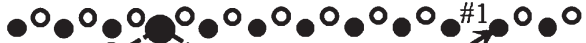

(c)

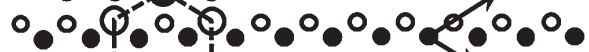

.

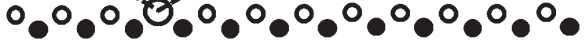

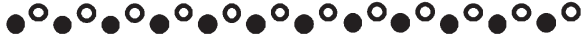

$$
\begin{aligned}
& \bigcirc: \operatorname{Nd}(z=0) \bigcirc: \operatorname{Nd}(z=1 / 2) \\
& \circ: \operatorname{Mg}(z=0) \bullet: M g(z=1 / 2)
\end{aligned}
$$

Fig. 5 Three relevant arrangements of Nd-atom columns to the precipitates resulting at $170^{\circ} \mathrm{C}$ for $2 \mathrm{~h}$, which are illustrated in the $[001]_{\mathrm{m}}$ projection and with the $[100]_{\mathrm{m}}$ direction parallel to the horizontal. Arrows with letters of \#1 and \#2 indicate two different types of second nearest neighbour positions defined in the hcp Mg-lattice (see text in detail). (a) $\mathrm{RE}=\mathrm{Y}, \mathrm{Gd}, \mathrm{Dy}$

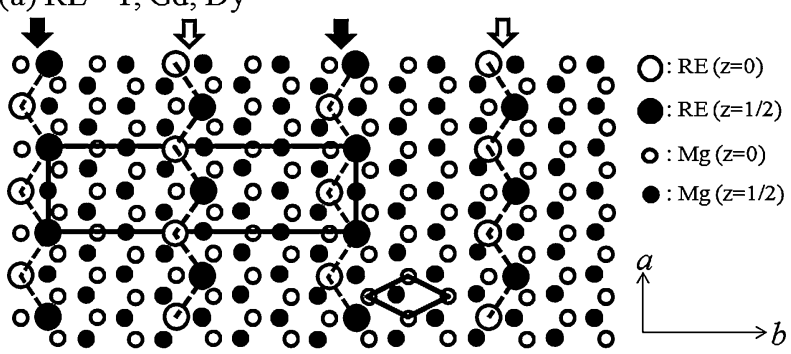

(b) $\mathrm{RE}=\mathrm{Nd}$

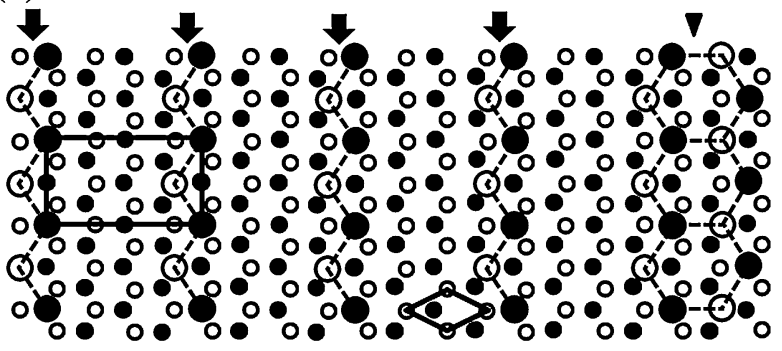

(c) $\mathrm{RE}=\mathrm{Sm}$

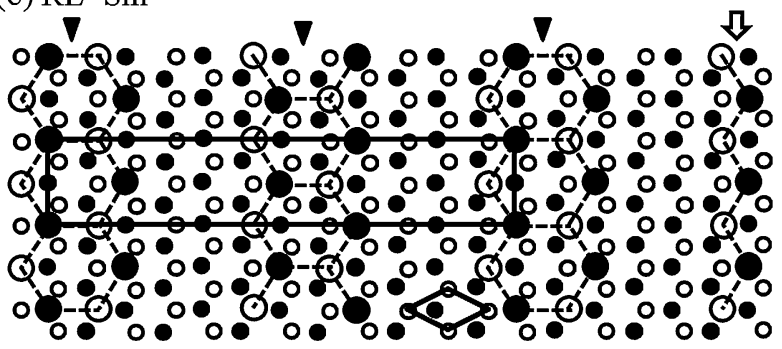

Fig. 7 Atomic arrangements of the precipitate phases resulting at the topstage of aging in various Mg-RE alloys: (a) RE $=\mathrm{Y}, \mathrm{Gd}$, Dy $;^{9-11,16)}$ (b) $\mathrm{RE}=\mathrm{Nd}$; (c) $\mathrm{RE}=\mathrm{Sm} .{ }^{15}$ ) They are illustrated in the $[001]_{\mathrm{m}}$ projection and with the $[210]_{\mathrm{m}}$ direction parallel to the horizontal. Two different types of arrows, i.e., a black arrow and a white arrow indicate the positions of one type of zigzag array and its inverted version, respectively, and an arrowhead indicate that of the hexagonal array. Unit cell profiles for the corresponding structures are indicated by thick solid lines.
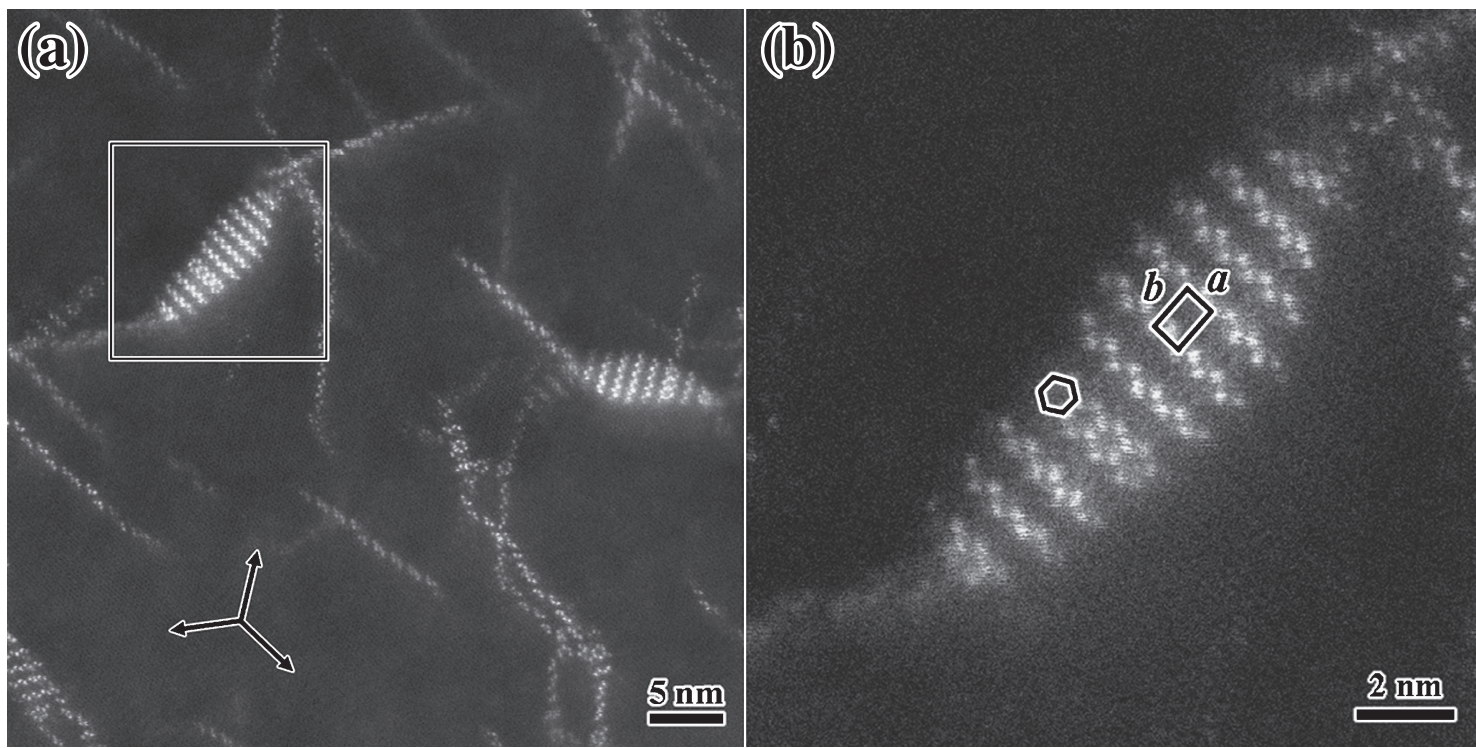

Fig. 6 Atomic-scale HAADF-STEM images obtained from the top-aged alloy at $170^{\circ} \mathrm{C}$ for $100 \mathrm{~h}$, taken with the incident beam parallel to the $[001]_{\mathrm{m}}$ direction: the image in an intermediate magnification (a) and the enlarged image from a local region indicated by a square. Note that three of the $[100]_{\mathrm{m}}$-type directions are indicated by a triad set of arrows in (a). In Fig. 6(b), a rectangle line with letters of $a$ and $b$ represents a unit cell profile of the constituent phase. 


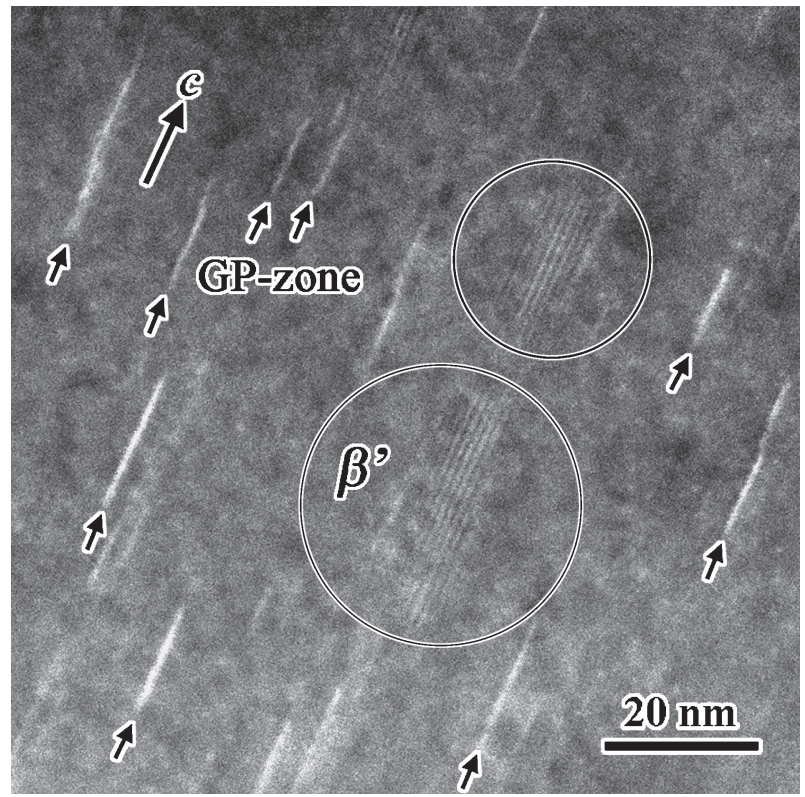

Fig. 8 An HAADF-STEM image obtained from the as-aged alloy at $200^{\circ} \mathrm{C}$ for $10 \mathrm{~h}$, taken with the incident beam parallel to the $[100]_{\mathrm{m}}$ direction. The contrast of a line segment is due to GP-zone, while that of a parallel set of line segments is of the $\beta^{\prime}$-precipitate.

without involving the inversion, and the structure unit in this case is of half the size of the above with $a=a_{0}=0.64 \mathrm{~nm}$, $b=2 \sqrt{3} a_{0}=1.14 \mathrm{~nm}, \quad c=c_{0}=0.52 \mathrm{~nm}$ and the same atomic ratio of $\mathrm{Mg}_{7} \mathrm{Nd}$. Assuming that a set of the alternatingly-inverted zigzag arrays are located closer than the case in Fig. 7(a), a periodic arrangement of the hexagonal arrays may appear, as is indicated by an arrowhead in Fig. 7(b). Such a situation is demonstrated by the observation presented by Fig. 6(b). It is reasonable to interpret that the precipitate in the $\mathrm{Mg}-\mathrm{Nd}$ alloy increasingly develops a long range ordered state with an advance of aging, then making many groups of such zigzag-components correlated with each other to form the zigzag arrays represented by Fig. 7(b). By contrast, the precipitate of the $\mathrm{Mg}-\mathrm{Sm}$ system has an opposite situation: the structure is mainly constructed of periodic arrangement of the hexagonal arrays (see Fig. 7(c)). ${ }^{15)}$ It is also reported that the zigzag arrays of an isolated type are sporadically found in the alloy, as indicated by a white arrow in Fig. 7(c).

Figure 8 shows an HAADF-STEM image obtained from the as-aged alloy at $200^{\circ} \mathrm{C}$ for $10 \mathrm{~h}$, taken with the incident beam parallel to the $[100]_{\mathrm{m}}$ direction. A number of precipitates enriched by $\mathrm{Nd}$ atoms can be recognized as bright contrasts, most of which take the form of a line segment with a thickness of sub-nm and a length of 10-20 nm parallel to the $c$-axis of the $\mathrm{Mg}$ matrix, as indicated by arrows. In addition, there exists a different type of precipitates showing a parallel set of line contrasts with an entire thickness of 10-15 nm and a length $15-30 \mathrm{~nm}$, two of which are enclosed by circles in the figure. As was evident from Fig. 3(a), this alloy has two different types of precipitate phases coexisting in the Mg matrix, that is, the GP-zones and the $\beta^{\prime}$-phase. These observations allow us to distinguish them as follows: the contrast of an isolated line segment is due to the GP-zone, while that of a parallel set of lines is to the

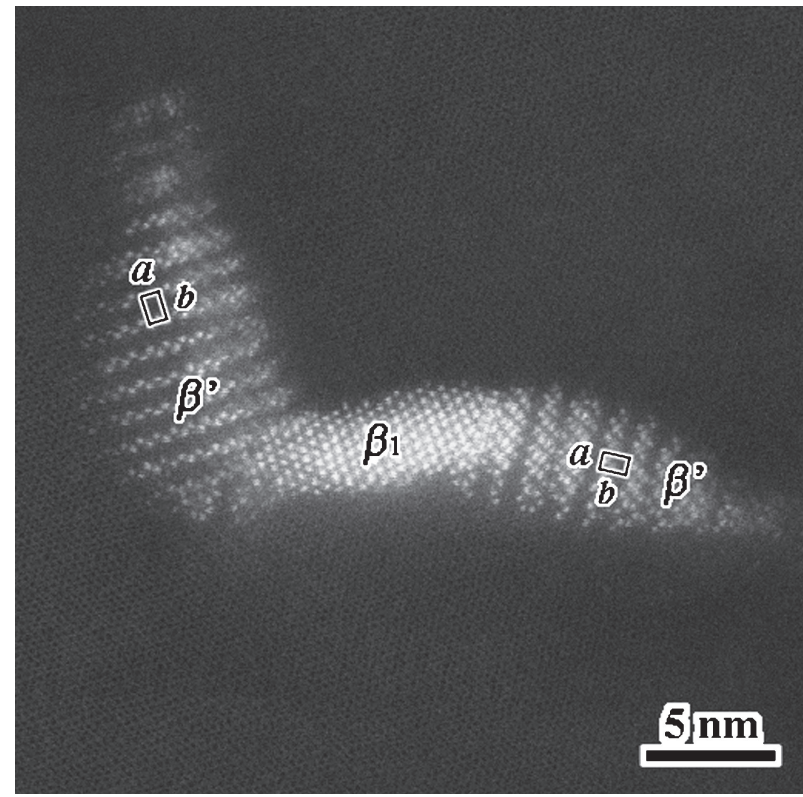

Fig. 9 An atomic-scale HAADF-STEM image obtained from an islandshaped precipitate present in the as-aged alloy at $250^{\circ} \mathrm{C}$ for $2 \mathrm{~h}$, taken with the incident beam parallel to the $[001]_{\mathrm{m}}$ direction. Rectangle lines with letters of $a$ and $b$ indicate unit cells constituting the corresponding grains.

$\beta^{\prime}$-phase. As for the latter, the interval of the parallel set of lines was estimated to be approximately $1 \mathrm{~nm}$, which agrees well with the interval between the zigzag arrays which is calculated by Fig. 7(b). In consideration of the above observations, it is undoubted that the GP-zones take the form of thin plates in parallel to both, the $[100]_{\mathrm{m}}$-type and the $[001]_{\mathrm{m}}$ directions.

Typical local structural features of precipitates resulting at different over-aging stages are presented in Figures 9-11. Figure 9 is an atomic scale HAADF-STEM image obtained from the as-aged alloy at $250^{\circ} \mathrm{C}$ for $2 \mathrm{~h}$, taken with the incident beam parallel to the $[001]_{\mathrm{m}}$ direction. This image highlights an island-shaped precipitate in the dark matrix of the Mg-lattice, which has a characteristic curving and twisting morphology with contrast features of bright dots in periodic arrangements. Apparently, the island is not composed of a single grain but rather three separate ones. Judging from the small contrast features observable, two of the grains, which are located at both ends of the island, can be identified as the $\beta^{\prime}$-phase with the two orientation variants. In between the $\beta^{\prime}$-grains, another type of grain with an apparently different contrast feature is present. In view of previous studies, ${ }^{7,12}$ the grain in the middle is certainly identified as the $\beta_{1}$-phase, which has an fcc structure with an atomic composition of $\mathrm{Mg}_{3} \mathrm{Nd}$ and a lattice parameter of $a=0.731 \mathrm{~nm}$. It appears that the $\beta_{1}$-grain has so grown that it acts as a piece of tile to cover the gap in between the two separate $\beta^{\prime}$-grains differing in orientation. When the alloy is excessively aged at temperatures above $200^{\circ} \mathrm{C}$, the $\beta^{\prime}$-phase rapidly reduces its volume, finally replacing itself with the thermodynamically stable $\beta_{1}$-phase. Figure 10 shows an HAADF-STEM image obtained from the as-aged alloy at $250^{\circ} \mathrm{C}$ for $9 \mathrm{~h}$, taken with the incident beam parallel to the $[001]_{\mathrm{m}}$ direction. At this aging stage, the $\beta_{1}$-phase becomes dominant all over the matrix (see Fig. 3(c)). In the middle of 

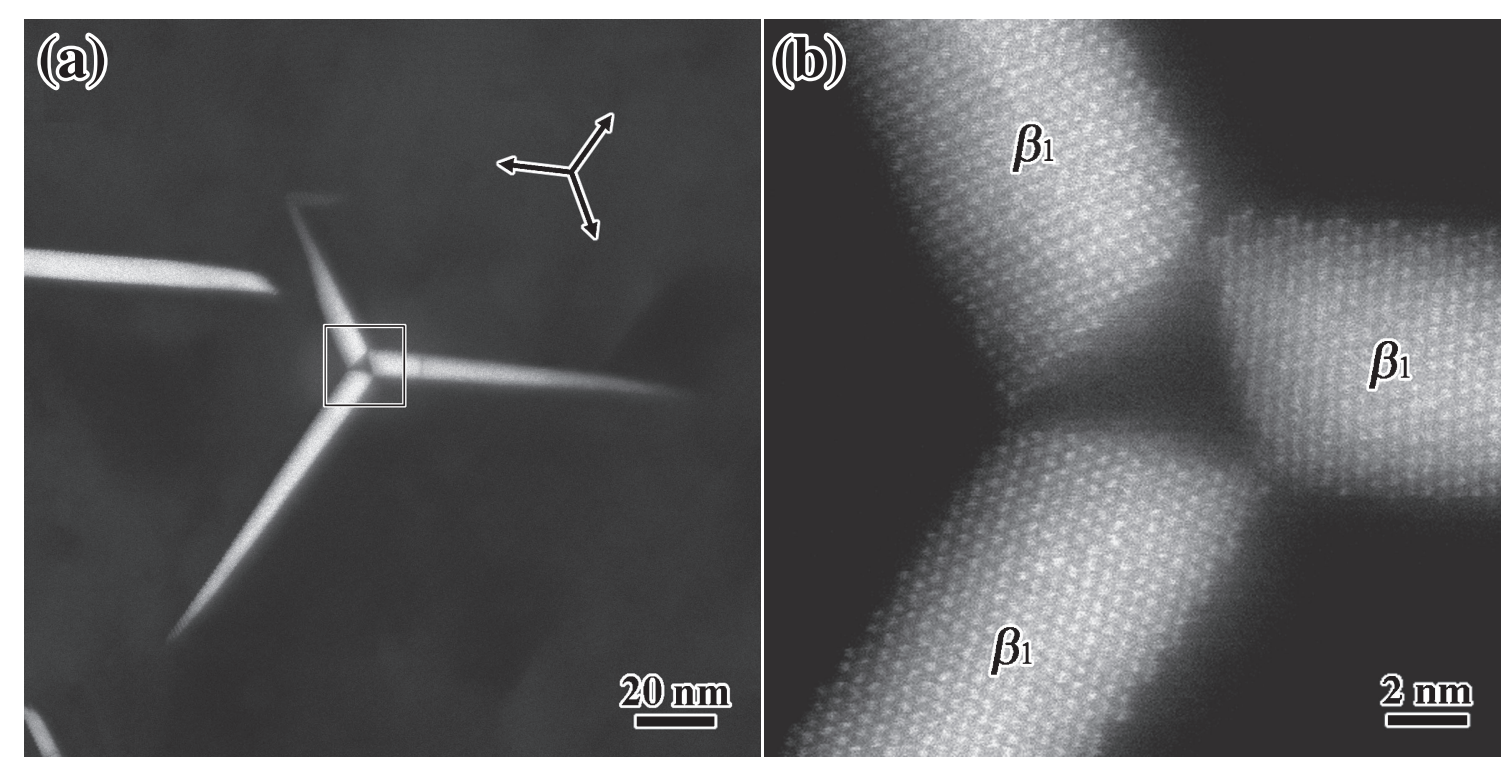

Fig. 10 Atomic-scale HAADF-STEM images of a triad of the $\beta_{1}$-precipitate with its orientation variants found in the over-aged alloy at $250^{\circ} \mathrm{C}$ for $9 \mathrm{~h}$, taken with the incident beam parallel to the $[001]_{\mathrm{m}}$ direction: the image in an intermediate magnification (a) and the enlarged image from a local region indicated by a square (b). Note that three of the $[100]_{\mathrm{m}}$-type directions are indicated by a triad set of arrows in (a).

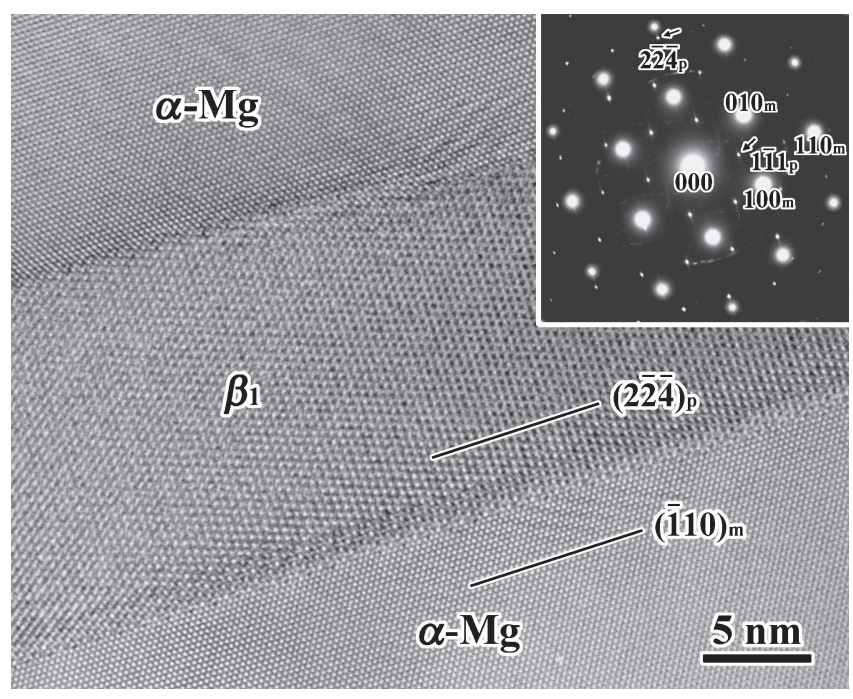

Fig. 11 An atomic-scale HETEM image of the $\beta_{1}$-phase together with its corresponding diffraction pattern in the inset, taken with the incident beam parallel to the $[001]_{\mathrm{m}}$ direction. Note that the $\beta_{1}$-precipitate has facets of the $(2 \overline{2} \overline{4})$ plane.

the images of Fig. 10, there appears a triad of the $\beta_{1}$ precipitates, which are mutually related as the orientation variants, extending radially in the three $[100]_{\mathrm{m}}$-type directions. They have grown with an average thickness of $6 \mathrm{~nm}$ and the length over $50 \mathrm{~nm}$ by this aging effect. Figure 11 is a $[001]_{\mathrm{m}}$-HRTEM image showing a local region where one of the variants of the $\beta_{1}$-phase is embedded in the $\mathrm{Mg}$-matrix, together with its corresponding diffraction pattern in the inset. Evidently, the $\beta_{1}$-phase precipitates with definite facets of $(2 \overline{2} \overline{4})_{\mathrm{p}}$, (the subscript letter of $\mathrm{p}$ denotes precipitate), which is parallel to a $(\overline{1} 10)_{\mathrm{m}}$ plane of the hexagonal Mg-matrix, and with definite crystallographic relations of $[001]_{\mathrm{m}} / /[110]_{\mathrm{p}}$ and $[110]_{\mathrm{m}} / /[112]_{\mathrm{p}}$.

\section{Conclusions}

The present microscopic investigations based on the HAADF-STEM technique have revealed the real precipitation behaviour of an $\mathrm{Mg}-0.5$ at $\% \mathrm{Nd}$ solid solution aged at certain temperatures ranging between $170^{\circ} \mathrm{C}$ and $250^{\circ} \mathrm{C}$. The precipitation sequence can be presented as $\mathrm{Mg}$-supersaturated solution $\rightarrow$ GP-zone $\rightarrow \beta^{\prime} \quad$ (orthorhombic) $\rightarrow \beta_{1}$ (fcc). The results are summarized as follows:

(1) The $\mathrm{Mg}-0.5$ at $\% \mathrm{Nd}$ solid solution shows an age-hardening effect under a test temperature of $170^{\circ} \mathrm{C}$ and has its hardness maximized $(\mathrm{HV} \sim 81)$ at an aging time of $100 \mathrm{~h}$. At the early stage of aging, the alloy has many fine precipitates taking the form of liner and/or curved segments with a thickness of sub-nm and a length ranging between 5 and $15 \mathrm{~nm}$. In the precipitates, the $\mathrm{Nd}$ atoms are induced to occupy second nearest neighbour positions in the $\mathrm{Mg}$ lattice. This ordering effect increasingly makes the Nd-enriched atom columns aligned in the form of zigzag chains in parallel to the $[100]_{\mathrm{m}}$-type directions of the $\mathrm{Mg}$-matrix, thus forming the planar GP-zones of ordered type.

(2) At the stage of top-aging $\left(170^{\circ} \mathrm{C}\right.$ for $\left.100 \mathrm{~h}\right)$, the alloy allows the $\beta^{\prime}$-phase to coexist with the GP-zones, taking the form of lens-shape with a thickness of $2-5 \mathrm{~nm}$ and a diameter of $10-20 \mathrm{~nm}$. The $\beta^{\prime}$-phase has an orthorhombic structure coherently connected to the matrix with an atomic ratio of $\mathrm{Mg}_{7} \mathrm{Nd}$ and lattice parameters of $a=a_{0}=0.64 \mathrm{~nm}, \quad b=2 \sqrt{3} a_{0}=1.14 \mathrm{~nm}, \quad c=c_{0}=$ $0.52 \mathrm{~nm}$.

(3) When the alloy is excessively aged at temperatures above $200^{\circ} \mathrm{C}$, both the GP-zones and the $\beta^{\prime}$-phase rapidly disappear and instead coarse precipitates of the stable $\beta_{1}$-phase $\left(\mathrm{Mg}_{3} \mathrm{Nd}\right)$ are formed with particular crystallographic relations of $[001]_{\mathrm{m}} / /[110]_{\mathrm{p}}$ and $[110]_{\mathrm{m}} / /[112]_{\mathrm{p}}$. 


\section{Acknowledgements}

This work was partly supported by the Center for Integrated Nanotechnology Support at Tohoku University and also by "Nanotechnology Network Project" of the Ministry of Education, Culture, Sports, Science and Technology (MEXT) of the Japanese Government.

\section{REFERENCES}

1) L. L. Rokhlin: Magnesium Alloys Containing Rare Earth Metals, London \& New York, (Taylar \& Francis, 2003).

2) T. E. Leontis: J. Metals 1 (1949) 968.

3) T. E. Leontis: J. Metals 3 (1951) 987.

4) R. V. London, R. E. Edelman and H. Markus: Trans ASM 59 (1966) 250.

5) R. S. Busk: Modern Metals 14 (1968) 43

6) J. F. Nie and B. C. Muddle: Scr. Mater 40 (1999) 1089.

7) J. F. Nie and B. C. Muddle: Acta Mater. 48 (2000) 1691.
8) C. Antion, P. Donnadieu, F. Perrard, A. Deschamps, C. Tassin and A. Pisch: Acta Mater. 51 (2003) 5335.

9) M. Nishijima, K. Yubuta and K. Hiraga: Mater. Trans. 48 (2007) 8487.

10) M. Nishijima, K. Hiraga, M. Yamasaki and Y. Kawamura: Mater. Trans. 47 (2006) 2109

11) M. Nishijima and K. Hiraga: Mater. Trans. 48 (2007) 10-15.

12) M. Nishijima, K. Hiraga, M. Yamasaki and Y. Kawamura: Mater. Trans. 49 (2008) 227-229.

13) K. Saito, M. Nishijima and K. Hiraga: Mater. Trans. 51 (2010) $1712-$ 1714.

14) K. Saito, A. Yasuhara and K. Hiraga: J. Alloy. Compd. 509 (2011) 2031.

15) M. Nishijima, K. Hiraga, M. Yamasaki and Y. Kawamura: Mater. Trans. 50 (2009) 1747-1752.

16) K. Saito, A. Yasuhara, M. Nishijima and K. Hiraga: Mater. Trans. 52 (2011) 1009-1015.

17) T. J. Pike and B. Noble: J. Less-Common Metals 30 (1973) 63.

18) M. Hisa, J. C. Barry and G. L. Dunlop: Proc. Third Int. Magnesium Conference, (The Institute of Materials, London 1997) p. 369.

19) M. Hisa, J. C. Barry, L. Gordon and G. L. Dunlop: Phil. Mag. A 82 (2002) 497. 